\title{
IDENTIDADE E LUGARIDADES: A ONTOLOGIA DO SER MIGRANTE
}

\author{
Danieli Barbosa de Araújo (Geografia- UEL) \\ Prof. Jeani Delgado Paschoal Moura (Orientadora)
}

\section{RESUMO}

Pôr-se a caminho e percorrer novos lugares acrescem lugaridades ao indivíduo, expressas como as experiências acumuladas no decorrer da vida, ao se travar conhecimento com novos espaços. No entanto, migrar e deixar o lugar de origem tratase de uma questão ontológica, que atinge o sujeito em seu modo de ser e de sua identidade. O lugar, na perspectiva fenomenológica, é um espaço de significações, com o qual se constrói intimidade e se revelam as essências, por meio das experiências dos que o habitam. As geografias pessoais estão intimamente ligadas à identidade de lugar, assim, colocar-se a caminho e migrar, implica em um conflito de identidade, que atinge o indivíduo e o instiga a um caminhar pensante, pois a sua experiência vai além da percepção e dos sentidos. Nesse sentido, substanciado pela fenomenologia geográfica, esta pesquisa promove uma reflexão da relação lugar, personalidade e identidade, bem como das implicações de se deixar o lugar de origem, visto que o processo migratório enseja transformações no ser e em sua identidade.

Palavras-chave: Lugar, identidade, fenomenologia.

\section{INTRODUÇÃO}

O objetivo deste texto é propor uma reflexão sobre o ato de migrar, ampliando o conceito deste para além do sentido de mudar de cidade, região, ou mesmo ir de um espaço a outro, em movimentos pendulares motivados por estudo e/ou trabalho. Buscase mostrar outras dimensões do processo migratório, tais como as implicações ontológicas do ato de migrar, ou seja, as percepções do ser com os espaços percorridos.

Para tanto, o mesmo considera a migração em seu sentido espaço-existencial, no qual o indivíduo, se existente, ocupa um determinado espaço e deposita sobre ele uma história de vida. Como expressa Dal Gallo (2010), esta dimensão, espaço existencial, está no cerne das discussões reflexivas dos geógrafos humanistas, sendo considerada essencial para o entendimento do ser-no-mundo.

O ser-no-mundo é uma condição existencial pelo espaço - temporal, que consiste nos laços intencionais e emocionais do indivíduo em direção a outros seres humanos e aos objetos que o circundam (MARANDOLA, 2008). Neste sentido, o homem nunca é visto separado do mundo, ele é e existe no mundo.

$\mathrm{O}$ fato de existir -a condição existencial- garante ao homem experienciar diferentes locais, traçar suas lugaridades (HOLZER, 2014), criar sentimentos e significados para lugares. Como demostra Marandola (2005) a experiência e a existência são indissociáveis, e, por não se separarem, não se podem furtar a uma referência

espacial. 


\section{SEMINÁRIO DE PESQUISA EM CIÊNCIAS HUMANAS - SEPECH \\ Humanidades, Estado e desafios didático-científicos \\ Londrina, 27 a 29 de julho de 2016}

Experienciar e existir ocorrem em um determinado espaço. Nesse aspecto, a existência só se consolida com base na experiência de lugares: o espaço existencial, o qual é o mundo fenomenológico.

A fenomenologia - diferente da ciência racionalista, pautada em testes e comprovações - busca novas formas de conhecimento através de percepções e vivências mundanas, levando em consideração o mundo vivido e a subjetividade do ser. A mesma, como afirma Gomes (2005), dá a possibilidade de reestabelecimento do contato entre o mundo real e o das significações.

Assim, substanciado pela fenomenologia geográfica, o presente trabalho busca pensar a migração partindo do conceito de lugar, chegando, deste modo, à dimensão ontológica do ser migrante, refletindo sua relação com os lugares, suas percepções e inquietações, na medida em que ele caminha de um espaço a outro.

Para tanto, é fundamental a seguinte reflexão: Se o lugar, na perspectiva fenomenológica é o espaço do apego, do aconchego, segurança e identidade, migrar provocaria transformação no ser e em sua identidade?

\section{LUGAR: INTIMIDADE, EXPERIÊNCIA E IDENTIDADE}

A compreensão da concepção de lugar, assim como seus dos vínculos e percepções - afetivas, identitárias, aversivas - depositadas pelo ser humano em um dado local é o que se pretende alcançar nesta pesquisa. Mais adiante, busca-se analisar como o ato de deixar os lugares afetivos envolve o sujeito em um processo de transformação de suas percepções e sentidos.

Na perspectiva fenomenológica, lugar pode ser pensado de diferentes formas e com diferentes significações, revelando as essências dos que o habitam. "Um lugar é um centro de ação e intenção, ele é 'um foco onde nós experimentamos os eventos significativos de nossa existência"” (RELPH, 1976, p. 42 apud Holzer, 2014). Assim, estes são locais que expressam intimidade, experiências e identidades, sendo estas distintas de indivíduo para indivíduo.

O lugar é um microcosmo, "o mundo do homem", o qual dá sentido à sua existência; logo, é mais que o lugar antropológico, mais que o habitus social ou casulo protetor psicológico. Ele é tudo isso ao mesmo tempo, e torna-se significativo, geograficamente, na relação corpórea e simbólica do sujeito com o local (MARANDOLA, 2012).

Assim, os locais passam a ser significativos ao homem que os habita. Este homem os percebe e lhes atribui valores e significados de forma singular. Neste sentido, "Duas pessoas não veem a mesma realidade. Nem dois grupos sociais fazem exatamente a mesma avaliação do meio ambiente" (TUAN, 1980, p.8). Enquanto um lugar pode ser extremamente significativo a uma pessoa, para outra, pode não ser. Os lugares com os quais temos mais intimidade, que visitamos com maior frequência, são mais significativos e afetivos a nós do que espaços pelos quais não criamos intimidade.

Os lugares íntimos - a casa e/ou cidade natal - são ambientes onde encontramos carinho, onde nossas necessidades fundamentais são consideradas, e onde encontramos segurança. São transitórios e pessoais, podem ficar gravados no mais profundo da memória e, cada vez que são lembrados, produzem imensa satisfação (TUAN, 1983). 


\section{SEMINÁRIO DE PESQUISA EM CIÊNCIAS HUMANAS - SEPECH \\ Humanidades, Estado e desafios didático-científicos \\ Londrina, 27 a 29 de julho de 2016}

Exemplificando o apego por sua cidade natal, seu lugar, uma moça da zona rural de Illinois, citada por Liberman Achie (1974) apud TUAN (1983, p.178), relata:

É tão irreal estar fora daqui. Fora daqui o mundo é irreal. Aqui sabemos onde a vida começa e acaba. Aqui a vida progride. É agradável pensar em sair deixando tudo para trás, mas é sempre agradável voltar para uma vida que é real, [...] nossa vida real está aqui.

Lançar-se no mundo, "fora daqui", como relatado, torna-se por algum momento "irreal", diferente de tudo que o indivíduo já viveu. "Aqui", como descrito por Liberman, esboça uma dimensão de afeto, um apego pelo lugar vivido, um enraizamento. Em outro exemplo, no delta interior do Níger, descrito por Gallais (1977), os povos que ocupam um mesmo espaço têm visões distintas a respeito deste.

Ao descrever o delta interior do Níger, expus detalhadamente as consequências da compartimentação sócio-ética ao nível infra-espacial como, por exemplo, os elos específicos que unem uma etnia a um dos elementos do meio (solo cultivável, savana de pastoreio, águas dos pesqueiros). Cada um desses elementos é determinado por organizações históricas, técnicas, sociais, de bens de raiz e religiosas que lhes são próprias, estranhas entre si, estruturalmente afastadas, embora vizinhas, ou superpostas dentro de uma percepção objetiva da distância. (GALLAIS, 1977, p.8)

Alguns valorizam o solo cultivável e desconhecem a savana, outros privilegiam o pastoreio e pouco veem importância nas águas dos pesqueiros. Cada grupo que vive dentro deste espaço tem funções e rotinas diferentes, demonstram habilidades em seus afazeres e apego ao seu grupo. Assim, as significações que os grupos têm do espaço, diferem entre si e cada qual valoriza e descreve a importância do espaço partindo das suas experiências e dos valores que estes construíram ao longo do tempo, enquanto viventes desta região.

É provável que, unindo os três grupos - citados no exemplo do Delta interior do Níger- para realizar relatos sobre o espaço, as descrições sejam distintas, pois será levada em consideração a experiência que cada qual traçou com seu espaço vivido.

As disparidades de significações presentes em um mesmo espaço, como por exemplo, em uma cidade, podem ser explicadas pelos sentimentos de topofilia, o "[...] elo afetivo entre a pessoa e o lugar ou ambiente físico" (TUAN, 1980, p.5) ou, seja, a expressão de um sentimento de carinho e afeição por um lugar. Ou ainda, pelo contrário, por um sentimento de não afeto, que também molda significações sobre o espaço e sobre os lugares.

Pensar o lugar, neste sentido, é considerar suas singularidades compostas por experiências, intenções e relações pessoais e, assim, compreendê-lo em sua significância.

$\mathrm{Na}$ experiência vivida, o espaço, o tempo e o lugar estão indissoluvelmente ligados. Na medida em que melhor conhecemos e vivenciamos um espaço, ele se torna um lugar permeado por sentimentos e significações. Para tanto, é necessário um tempo de comunhão e de vivência com um certo espaço, para que ele venha a se tornar um lugar. "O que começa como espaço indiferenciado transforma-se em lugar à medida que o conhecemos melhor e o dotamos de valor" (TUAN, 1983, p. 14). 


\section{SEMINÁRIO DE PESQUISA EM CIÊNCIAS HUMANAS - SEPECH \\ Humanidades, Estado e desafios didático-científicos \\ Londrina, 27 a 29 de julho de 2016}

“O lugar é uma pausa no movimento. Essa é uma relação entre tempo e lugar [...] a pausa que permite a localização para tornar o lugar o centro de significados que organiza o espaço do entorno" (TUAN, 2011, p. 12). A pausa no movimento revela o lugar, que outrora foi um espaço. Permanecer um determinado tempo em um lugar, ou seja, dar uma pausa no movimento, - movimento este que representa os novos e outros lugares a serem percorridos, como outras cidades -, permite ao homem criar significações por este local, construindo afeições e desafetos, dotando-o de valoração.

Os lugares e as paisagens assumem concepções e significados a partir das vivências, dos contatos, das identidades, das subjetividades humana inseridas sobre ele (LOPES, 2010). Homem, meio e objetos apresentam relação simbólica e de interação, todos gerando significância e características únicas aos lugares.

Assim, pensar o lugar vai além de seus aspectos locacionais, físicos ambientais. Pensar o lugar implica considerar as experiências humanas e sentimentos que lhes são imanentes. "[...] O ser humano não é exclusivamente razão; mas igualmente alguém que tem sensações, isto é, que sente, que percebe, que forma suas imagens a partir da subjetividade" (LOPES, 2010, p.26-28).

É por essas significações, por estes sentimentos depositados nos lugares que migrar leva o indivíduo a um questionamento ontológico, no qual o lugar a ser deixado não é somente um local de moradia, mas um lugar que traz uma história de vida, que liga o homem às suas lembranças, ao seu mundo vivido, à sua existência.

\section{A ONTOLOGIA DO SER MIGRANTE}

Certamente, são inúmeros os motivos que estão na base do processo migratório, como a busca por um emprego, estudos, melhores condições de vida, conflitos religiosos, civis, políticos, entre tantos outros.

Entretanto, há algo em comum entre esses processos migratórios: A espaciosidade e o apinhamento. O primeiro, está intimamente associado com a sensação de estar livre. Liberdade implica em espaço suficiente onde se atuar. Estar livre tem diversos níveis de significados, sendo o mais importante deles a capacidade de transcender a condição presente, e a forma mais simples como esta transcendência se manifesta é o poder básico de locomover-se (TUAN, 1983).

Já pinhamento remete a ideia de limitação. O jovem da pequena cidade, por exemplo, a considera apinhada em sentido econômico porque a mesma não oferece empregos suficientes. Em um sentindo psicológico, o faz porque a pequena cidade impõe muitas restrições sociais ao seu comportamento.

Assim, a falta de oportunidade na esfera econômica e de liberdade na esfera social fazem o mundo das pequenas cidades parecerem estreitos e limitados (TUAN, 1983). Neste sentido, com o processo de migração, o indivíduo busca encontrar, para além de seu local atual, um novo espaço que lhe forneça melhores condições, que lhe permita progredir em relação a sua situação atual.

A busca por novos espaços revela ao indivíduo diferentes microterritorialidades (HOLZER, 2014), as quais exibem costumes, hábitos e tradições singulares. As microterritorialidades passam a ser desvendadas no "movimento", no percorrer de novas lugaridades, ou seja, no ato de migrar. 


\section{SEMINÁRIO DE PESQUISA EM CIÊNCIAS HUMANAS - SEPECH \\ Humanidades, Estado e desafios didático-científicos \\ Londrina, 27 a 29 de julho de 2016}

Logo, cursar novos lugares evidencia como os mesmos são distintos, marcados por experiências intensas, por costumes e hábitos transmitidos de geração a geração. Tais particularidades são facilmente reconhecíveis pelos "de fora" e pelos que estão "dentro" de um determinado lugar.

As lugaridades se projetam nos espaços de vida, os quais se intensificam na medida em que se "caminha", se conhece e se vivencia tais espaços. Ao migrar, há um acúmulo de lugaridades, de vivências. "O lugar é a segurança e o espaço é a liberdade: estamos ligados ao primeiro e desejamos o outro" (TUAN, 1983, p. 5). Vive-se em um lugar, mas almejam-se outros e este almejar incorpora novos espaços e novas histórias que compõem o que chamamos de "espaços de vida".

Sejam nos movimentos diários ou nas mobilidades que se tornam permanentes, os espaços de vida vão sendo desenhados cotidianamente. Na figura 1, nas conchas dos homens, de Moles e Rohmer, citado por Frémont (1976), ilustra-se as sucessivas conquistas do espaço vivido, atreladas aos deslocamentos, ao percorrer de novos espaços que acrescem lugaridades. Ilustra-se, também, como a intimidade com o espaço vai sendo diminuída na medida em que novos espaços vão sendo percorridos.

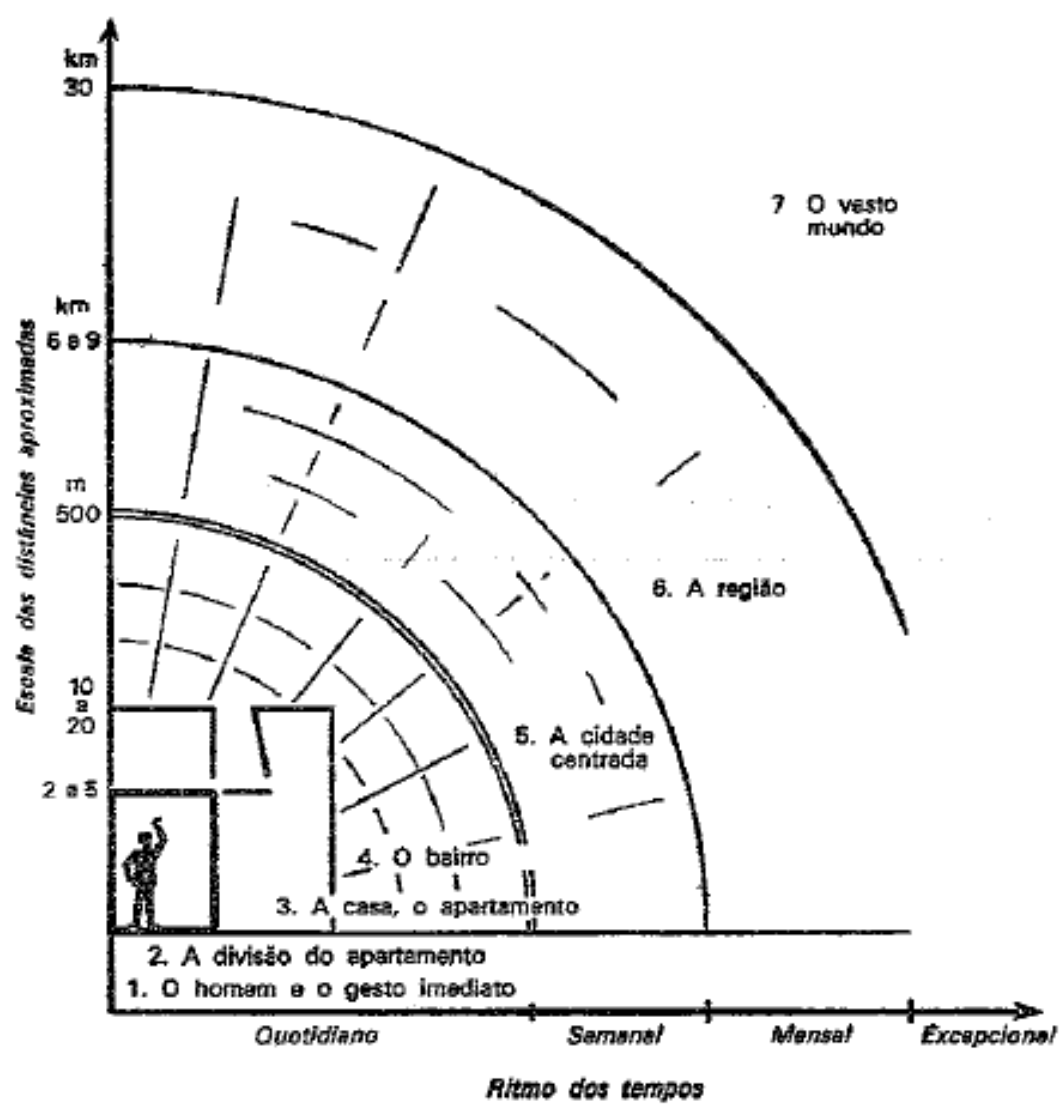

Figura 1: Conchas dos homens

Fonte: Moles e Rohmer, apud Frémont (1976).

A casa e o apartamento seriam refúgios, rodeados apenas por seres e objetos familiares. O bairro seria ainda uma extensão da casa, um espaço familiar, diferente da região na qual o indivíduo vê e passa a ser visto como um estranho, "a região conduz 


\section{SEMINÁRIO DE PESQUISA EM CIÊNCIAS HUMANAS - SEPECH \\ Humanidades, Estado e desafios didático-científicos \\ Londrina, 27 a 29 de julho de 2016}

para lá do cotidiano e do familiar" (FRÉMONT,1976, p.31). O vasto mundo é a zona de viagens e exploração, o desconhecido, mais ou menos conhecido.

Cada concha apresenta, em um determinado momento, uma autossuficiência do indivíduo. Assim, quando este não consegue encontrar mais o que precisa dentro deste espaço, e passa a se sentir apinhado, ou mesmo sente a ausência de espaciosidade, ele procura por outros locais. O refúgio, expresso pela casa e o apartamento, é um espaço suficiente para a criança, por exemplo, a qual encontra tudo o que precisa dentro deste espaço.

A casa, em Bachelard (1993), é o nosso canto no mundo, é o nosso primeiro universo, ambiente em que vivem os seres protetores. Como expressa Gratão, sobre a casa em Bachelard

A casa é analisada enquanto um espaço que, por excelência, cria as raízes do homem no mundo. A casa enraíza em nós. A casa é o nosso 'canto do mundo'. O canto do ser no mundo, abrigo, amparo, proteção onde se conjuga, articula a intimidade com o mundo. A casa oferece ao homem a segurança da restauração, a segurança do repouso, a segurança do acolhimento. A intimidade reencontrada no interior de uma casa confere ao homem a confiança de ser frente aos apelos do mundo. Só um homem feliz na sua intimidade reencontrada, está certo de ter saído de casa e retornado ao que há no mundo, quando revivido a intimidade da casa vivida (GRATÃO, 2015, p. 153)

A casa é abrigo, lugar onde se fica protegido. No entanto, é preciso lançar-se no mundo. Na medida em que o indivíduo cresce, a locomoção se torna necessária. Ir à escola, por exemplo, é um ato que não cabe mais ao refúgio, ao abrigo, é preciso ir além. As necessidades de um jovem, de um adulto vão ultrapassar, com o tempo, o espaço da cidade, ampliando-se para a região, a qual envolve outras cidades, levando-o de acordo com suas necessidades para o vasto mundo.

Mas, como os migrantes lidam com a problemática de viver numa situação inalienável de estranhamento e negociação de estar em outro lugar? (DAL GALLO, 2010).

É importante considerar que o ato de migrar está além do seu sentido espacial, de ir de um espaço a outro. O indivíduo quando migra, deixa seu lugar, ainda que o carregue em suas lembranças. Deixa objetos, tarefas do cotidiano, familiares, amigos e pessoas que compuseram, em alguma medida, sua história e marcaram sua existência.

Deixar seu lugar, portanto, o migrar implica no distanciamento daquilo que lhes dá segurança existencial (MARANDOLA JR., 2008). O que teria o potencial efeito de provocar um estado de insegurança e incerteza, pois o deslocar-se afrouxaria a conectividade/receptividade sujeito-lugar, colocando o indivíduo em um estado de "suspensão", em um abalo de sua segurança existencial (DAL GALLO, 2010).

Em um exemplo de distanciamento e abalo de sua segurança existencial, Tuan (1983) expressa:

Nos Estados Unidos, os filhos dos trabalhadores rurais volantes sofrem porque, entre outras razões, não têm durante um período de tempo um lugar que possam identificar como deles. Pedro, por exemplo, é um menino de sete anos que viaja com seus pais, para cima e para baixo, na 


\section{SEMINÁRIO DE PESQUISA EM CIÊNCIAS HUMANAS - SEPECH \\ Humanidades, Estado e desafios didático-científicos \\ Londrina, 27 a 29 de julho de 2016}

costa leste. Raramente permanecem muito tempo em uma fazenda. Pedro ajuda a colher frutas e verduras, vai à escola quando pode. [...] Todos os seres humanos têm seus próprios pertences e talvez todos tenham necessidade de um lugar seu, quer seja uma cadeira no quarto ou um canto preferido em qualquer veículo. (TUAN, 1983, p. 47)

Pedro, o menino que vive em constante processo de migração, não mantém uma conectividade com um lugar, nem mesmo estabelece sentidos de segurança e pertencimento, visto que estes se dão na "pausa no movimento", no estar em um local, fazendo dele, com o tempo de permanência, um lugar.

O migrante, ao chegar em um novo lugar, se defronta com o diferente, cujos objetos, pessoas e sensações lhe são desconhecidos. Esse embate permeia a condição existencial do migrante, o qual passa a negociar, com o novo espaço, diariamente seu pertencimento, em uma condição de tensão entre o novo local habitado e o lugar de onde migrou. Assim, tal embate solicita que ele equilibre as preponderâncias e exigências da terra natal e do novo lugar (DAL GALLO, 2010).

Neste sentido, dizemos que o ato de migrar atinge a questão ontológica do ser, pois o indivíduo vive em uma constância entre adaptar-se e compreender o novo local para onde migrou, e conviver com as lembranças, hábitos e costumes de seu lugar natal. O ser migrante, "pode, ainda que esteja presente corporeamente no local de destino, não se integrar, mantendo suas ações e expectativas voltadas para sua terra natal" (DAL GALLO, 2010, p.28).

Essa adaptação ao novo, que abala sua existência, varia de indivíduo para indivíduo. De início, há um estranhamento provocado pelo deslocamento de seu lugar de origem; em seguida, ocorre a possibilidade de um enraizamento. Assim, "É uma necessidade intrínseca ao migrante a constituição de seus lugares para a realização de sua existência" (DAL GALLO, 2010, p.28).

Constituir um lugar é estar ligado a ele, em seu sentido fenomenológico, esboçando intimidade, vivência e histórias vividas. Essa constituição, ou seja, ligação a um lugar, é importante, pois o homem interioriza suas experiências como parte de sua existência.

Em todos estes casos, o migrante experiencia uma situação de "transitoriedade ontológica" (DAL GALLO, 2010), isto é, uma busca do migrante por situar-se no mundo e retomar sua segurança existencial. Portanto, reafirma-se que migrar está além do sentido locacional, de ir de um espaço a outro. Migrar, envolve a dimensão ontológica do ser, ou seja, sua existência.

\section{CONSIDERAÇÕES FINAIS}

Tendo como base o conceito de lugar - local de aconchego, intimidade, segurança, o qual exerce forte influência experiencial ao indivíduo migrante percebe-se que ao deixá-lo, e, consequentemente, deixar para trás seu lugar repleto de costumes, pessoas, objetos e serviços conhecidos- faz com que o indivíduo enfrente uma insegurança existencial. Ou seja, sua segurança advém do contato e da intimidade, logo, estar frente ao novo gera insegurança, medo, indecisão e questionamentos. 


\section{SEMINÁRIO DE PESQUISA EM CIÊNCIAS HUMANAS - SEPECH \\ Humanidades, Estado e desafios didático-científicos \\ Londrina, 27 a 29 de julho de 2016}

Assim, percebe-se que o ser humano, além de um ser espaço-existencial, é, também, um ser espaço-experiencial, o qual cunha sentimentos pelos lugares vividos, que na medida que é existente, experiência espaços e deposita sobre eles sentimentos.

Neste sentido, ao migrar, há uma busca por inserir-se em uma realidade geográfica alheia. $\mathrm{O}$ indivíduo busca, frente ao processo de migração, amortecer os abalos e implicações de seu deslocamento, de maneira que possa dar continuidade a sua narrativa existencial (DAL GALLO, 2010).

Destarte, este ensaio buscou, portanto, uma reflexão do processo migratório para além do seu sentido espacial, considerando-o em seu sentido espaço existencial e experiencial.

Ainda que breves em suas discussões, o presente diálogo possibilitou a reflexão sobre os efeitos de se deixar o lugar de origem em busca de novos espaços e como o ato de migrar influencia na personalidade e identidade do indivíduo, que se vê frente a um espaço desconhecido, de adaptação e de insegurança.

\section{REFERÊNCIAS}

BACHELARD, Gaston. A poética do espaço. Trad. Antônio de Pádua Danesi. São Paulo: WMF Martins Fontes, 1993.

DAL GALLO, Priscila M. A experiência de ser migrante: entre identidades e transitoriedades.70f. Monografia (Bacharelado em Geografia) - Instituto de Geociências, Universidade Estadual de Campinas, Campinas. 2010.

FRÉMONT, A. A região, espaço vivido. Portugal, Coimbra: Livraria Almedina, 1976.

GALLAIS, J. Alguns aspectos do espaço vivido nas civilizações do mundo tropical. Boletim Geográfico, Rio de Janeiro: Geografia, Periódicos IBGE a.1,- n.1 IBGE, 1977. p. 1-14.

GOMES, Paulo. Geografia e modernidade. 5.ed. Rio de Janeiro: Bertrand Brasil, 2005.

GRATÃO, Lucia. A 'casa' de Bachelard e sua potência poética na educação. ENEIMAGEM, Anais... V Encontro Nacional de Estudos da Imagem. Londrina, v.4. p. 149- 159, 2015.

HOLZER, Werther. Sobre territórios e lugaridades. Cidades, grupo de estudos urbanos, UNESP, v. 10, n. 17, p. 19-29, out. 2014.

LOPES, J.G. A geografia humanística como ferramenta de ensino. Geosaberes: Revista de estudos geoeducacionais. Ceará. v. 1, n. 02. p. 26-38, dez. 2010.

MARANDOLA, JR, Eduardo. Arqueologia fenomenológica: em busca da experiência.

Terra Livre, Ano 21, v.2, n.25, p.67-79, jul./dez. 2005. 


\section{SEMINÁRIO DE PESQUISA EM CIÊNCIAS HUMANAS - SEPECH \\ Humanidades, Estado e desafios didático-científicos \\ Londrina, 27 a 29 de julho de 2016}

MARANDOLA, JR, Eduardo. Mapeando" Londrinas": imaginário e experiência urbana. Geografia, v. 33, n. 1, p. 103-126, 2008.

MARANDOLA JR, Eduardo. Da existência e da experiência: origens de um pensar e de um fazer. Caderno de Geografia, Belo Horizonte, v. 15, n. 29, p. 49-67, 2005.

TUAN, Yi--Fu. Topofilia: um estudo da percepção, atitudes e valores do meio ambiente. Trad. Lívia de Oliveira. São Paulo: Difel, 1980.

Espaço e lugar: a perspectiva da experiência. São Paulo: Difel, 1983.

Inverno 2011. Disponível em: http://www.uff.br/posarq/geograficidade/revista/index.php/geograficidade/article/view/1 /pdf\# Acesso em: 27 de maio 2016 